\title{
PROPAGAÇÃO VEGETATIVA DO JEQUITIBÁ-ROSA (Cariniana estrellensis (Raddi) KUNTZE) POR ESTAQUIA ${ }^{1}$
}

\author{
William Hernandez ${ }^{2}$, Aloisio Xavier ${ }^{3}$, Haroldo Nogueira de Paiva ${ }^{3}$ e Ivar Wendling ${ }^{4}$
}

\begin{abstract}
RESUMO - O presente trabalho teve como objetivo desenvolver uma metodologia para a propagação vegetativa do jequitibá-rosa (Cariniana estrellensis (Raddi) Kuntze), por meio da técnica de estaquia, avaliando-se a sobrevivência e capacidade produtiva das cepas em coletas sucessivas de estacas em jardim clonal. A sobrevivência, o enraizamento, a altura, o vigor e a biomassa radicular e foliar das estacas, em razão da aplicação de diferentes dosagens do regulador de crescimento ácido indolbutírico (AIB) e do tipo de estaca utilizado. O jardim clonal foi constituído de plantas oriundas a partir de mudas de material seminal, com uma densidade de nove plantas por $\mathrm{m}^{2}$, estabelecidas em solo. Foram feitas avaliações quanto ao enraizamento das estacas em dois períodos de tempo diferentes do ano, em casa de vegetação (aos 120 dias), em casa de sombra (aos 140 dias) e em pleno sol (aos 170 dias) após o estaqueamento. A aplicação do AIB não teve efeito na maioria das características avaliadas. No entanto, quanto ao tipo de estaca, as apicais foram as que apresentaram maiores valores para as características estudadas. A sobrevivência das cepas foi de $100 \%$ e a produção de brotações mostrou tendência crescente nas coletas sucessivas. Conclui-se que a propagação vegetativa do jequitibá-rosa pela técnica de estaquia é viável, principalmente quando se utilizam estacas apicais, e a aplicação de AIB não mostrou efeitos destacados que indiquem a sua utilização na propagação do jequitibá-rosa pela estaquia.
\end{abstract}

Palavras-chave: Regulador de crescimento; Enraizamento de estacas; Propagação de plantas.

\section{VEGETATIVEPROPAGATION OF JEQUITIBÁ-ROSA (Cariniana estrellensis (Raddi) KUNTZE) BY CUTTINGS}

\begin{abstract}
The present studyaimed to develop a vegetative propagationmethodology for jequitibá-rosa (Carinianaestrellensis (Raddi) Kuntze) by using the technique of cuttings evaluating the survival and productive capacity of the strains in successivecuttings collections in the clonal garden.Moreover, wereevaluated the rooting, height, vigor and root biomass and leaf cuttings due to the application of different dosages of growth regulator (IBA) and type of cutting. The clonal garden was built from plants derived from seedlings coming from seminal material with a density of 9 plants per $m^{2}$ established directly in the soil. Rootingevaluations were performedin two periods of the year, in a greenhouse (at 120 days), in the shade (at 140 days) and atfull sun (at 170 days), after the establishment. The application of IBA did not influencemost of the evaluated characteristics; however, as for the type of cutting, the apical stumps presented the greatest values for the studied characteristics. The survival of strains was $100 \%$ and production of shoots showed a rising trend in successive collections. It is concluded that the vegetative propagation of jequitibá-rosa by cutting technique is feasible, especially when using apical cuttings. IBA application promotedno significant effects, indicating that its use is not necessaryforpropagation by cuttings of jequitibá-rosa.
\end{abstract}

Keywords: Growth regulator; Rooting; Plants propagation.

\footnotetext{
${ }^{1}$ Recebido em 07.06.2011 aceito para publicação em 03.09.2013.

${ }^{2}$ Instituto de Pesquisas e Serviços Florestais (INISEFOR) da Universidade Nacional da Costa Rica. E-mail: <william.hernandez.castro@una.cr>

${ }^{3}$ Universidade Federal de Viçosa, Centro de Ciências Agrárias, Departamento de Engenharia Florestal. E-mail: <xavier@ufv.br>; $<$ hnpaiva@ufv.br>.

${ }^{4}$ Empresa Brasileira de Pesquisa Agropecuaria (EMBRAPA). E-mail: <ivar@cnpf.embrapa.br>.
} 


\section{INTRODUÇÃO}

O Brasil possui diversidade de espécies florestais com grande potencial produtivo; no entanto, há carência de informações sobre os aspectos de propagação vegetativa dessas espécies que limita a disponibilidade de mudas no mercado, assim como no desenvolvimento de plantios comerciais. Atualmente, é reconhecida a necessidade de maior número de dados e informações sobre as espécies de importância econômica e ecológica, para atender as exigências do mercado consumidor de madeiras e outros produtos florestais e abastecer os programas de restauração ecológica. A ampliação do conhecimento sobre a produção de mudas florestais com qualidade, quantidade e diversidade, suficiente para o estabelecimento de povoamentos com espécies nativas para diversas finalidades, constitui fator fundamental para o desenvolvimento da silvicultura de espécies nativas no Brasil.

A espécie Cariniana estrellensis, vulgarmente conhecida como jequitibá-rosa, pertencente à família Lecythidaceae, é uma árvore heliófita, característica da floresta latifoliada semidecídua, comumente com 30 a 50 m de altura e 70 a 100 cm de diâmetro. É localizada nos Estados do Espírito Santo, do Rio de Janeiro, de Minas Gerais, de São Paulo e do Mato Grosso do Sul, tanto na floresta pluvial atlântica como na latifoliada semidecídua da bacia do Paraná (LORENZI, 2002). Ocorre nas baixadas e encostas úmidas, sendo encontrada em pequenos grupos, no estrato superior da Floresta Ombrófila Densa (Floresta Atlântica), na formação Baixo-Montana e na Floresta Estacional Semidecidual. O jequitibá-rosa possui tolerância moderada à luz direta, durante os primeiros anos, e o seu crescimento varia de moderado a rápido (CARVALHO, 1994).

Atualmente a propagação de jequitibá-rosa no Brasil é feita por sementes, situação que limita a disponibilidade de suas mudas e o desenvolvimento de seus povoamentos. A propagação vegetativa surge como alternativa viável para a produção de mudas dessa espécie, o que permite a implantação de povoamentos comerciais ou para outros fins. A utilização da propagação vegetativa com espécies florestais, associada a programas de melhoramento, tem como finalidades acelerar o crescimento, aumentar a produtividade e gerar madeira de qualidade e homogênea, pela multiplicação de plantas selecionadas (ALFENAS et al., 2004).
Dentre os métodos de propagação vegetativa, a estaquia constitui uma das técnicas, cujos princípios já são bem conhecidos para as espécies de Eucalyptus, sendo amplamente adotada na clonagem de árvores, o que permitiu o desenvolvimento da silvicultura clonal de forma intensiva em diversas partes do mundo (XAVIER et al., 2009). Essa técnica é uma das que se tem maior domínio e conhecimento científico, representando um dos maiores avanços tecnológicos na área florestal (ASSIS, 1997). Antes do surgimento das técnicas de miniestaquia e microestaquia, a estaquia foi uma das que proporcionou maior viabilidade econômica para o estabelecimento de plantios clonais, pela multiplicação de genótipos selecionados, em curto período de tempo (PAIVA; GOMES, 2005).

Para as espécies nativas brasileiras, há pouca informação sobre o uso da propagação por estaquia, que permita uma produção comercial. Recentemente, estudos têm indicado que a multiplicação vegetativa por miniestaquia, a partir de material juvenil de origem seminal, é tecnicamente viável para algumas espécies florestais nativas, como cedro-rosa (Cedrela fissilis), angico-vermelho (Anadenanthera macrocarpa), jequitibá-rosa (Cariniana estrellensis), entre outras, tornando-se uma alternativa para a produção de mudas durante todo ano, sobretudo nas situações em que a semente é insumo limitante (XAVIER et al., 2009).

Alguns estudos mostraram que a propagação vegetativa para algumas espécies nativas é viável, Rocha (2002), por exemplo, avaliou a técnica de enxertia em Cariniana legalis, obtendo-se 45\% de sobrevivência dos enxertos aos 90 dias de idade, em que foram utilizadas mudas propagadas por sementes, com seis meses de idade, como porta-enxerto, e propágulos coletados da árvore matriz de interesse como enxertos. Santos (2002), utilizando a técnica de miniestaquia, observou que a aplicação dos reguladores de crescimento AIB e ANA influenciam significativamente no enraizamento das miniestacas de jequitibá-rosa, com obtenção de $60 \%$ de enraizamento, quando foi aplicado o ANA, com uma concentração de $4.000 \mathrm{mg} \mathrm{L}^{-1}$, enquanto com o AIB, o enraizamento das miniestacas, de modo geral, foi de 47,9\%.

A carência de estudos sobre a propagação vegetativa com jequitibá-rosa, bem como a importância que tem a espécie no contexto florestal no Brasil e o conhecimento sobre novos sistemas de produção de espécies nativas em geral, justifica o desenvolvimento de estudos que 
permitam gerar informações sobre a propagação dessa espécie. Dessa forma, o objetivo deste trabalho foi desenvolver uma metodologia para a propagação vegetativa do jequitibá-rosa, por meio da técnica de estaquia, avaliando-se a sobrevivência e capacidade produtiva das cepas em coletas sucessivas de estacas em jardim clonal e a sobrevivência, o enraizamento, a altura, o vigor e a biomassa radicular e foliar das estacas, em razão da aplicação de diferentes dosagens do regulador de crescimento ácido indolbutírico (AIB) e do tipo de estaca utilizado.

\section{MATERIAL E MÉTODOS}

Este estudo foi realizado no viveiro de pesquisas do Departamento de Engenharia Florestal, da Universidade Federal de Viçosa, em Viçosa, Minas Gerais, durante o ano de 2010. O município de Viçosa localiza-se na Zona da Mata do Estado de Minas Gerais, à altitude de $652 \mathrm{~m}$, situando-se nas coordenadas de $20^{\circ} 45^{\prime}$ de latitude sul e $42^{\circ} 51^{\prime}$ de longitude oeste. O clima é do tipo Cwb segundo Köeppem, classificado como subtropical moderado úmido, com precipitação média anual de $1.341 \mathrm{~mm}$ e umidade relativa do ar em torno de $80 \%$. A temperatura média anual é de $19^{\circ} \mathrm{C}$, sendo a média das máximas de $21,6{ }^{\circ} \mathrm{C}$ e a das mínimas de $14^{\circ} \mathrm{C}$ (ROCHA; FIALHO, 2010).

\subsection{Formação do jardim clonal}

As mudas de jequitibá-rosa (Cariniana estrellensis), utilizadas no experimento, foram obtidas a partir de sementes coletadas em árvores matrizes localizadas na região de Viçosa-MG. A seleção das matrizes e coleta das sementes foram realizadas pela Sociedade de Investigação Florestal - SIF/UFV. As mudas ao atingirem uma altura de $30 \mathrm{~cm}$ aproximadamente foram transplantadas em canteiros a pleno sol, numa densidade de nove mudas por metro quadrado, para um total de 36 mudas por canteiro, as quais formaram o jardim clonal para posterior coleta de brotações, para confecção das estacas. Fora de uma sequência operacional, foi realizada uma adubação de base, aplicando-se 50 g/planta do adubo N:P:K (8-28-16), colocado no fundo da cova. Posteriormente, as mudas foram adubadas, a cada 60 dias, com $100 \mathrm{~g} / \mathrm{m}^{2}$ de sulfato de amônio, $50 \mathrm{~g} / \mathrm{m}^{2}$ de superfosfato simples e $50 \mathrm{~g} / \mathrm{m}^{2}$ de cloreto de potássio. Os tratos culturais das mudas constituíram-se em duas de irrigações diárias, podas seletivas de manutenção e coleta das estacas necessárias à experimentação. As cepas, com altura em torno de $40 \mathrm{~cm}$, foram conduzidas a uma decepa para obtenção de multibrotações, destinadas ao fornecimento de estacas para os experimentos de enraizamento.

A primeira coleta das estacas foi feita após 30 dias da decepa, quando essas apresentavam tamanho suficiente (aproximadamente brotações com uns $50 \mathrm{~cm}$ de comprimento), em função dos diferentes tipos de estacas (apical, intermediária e basal) utilizados nos experimentos. Posteriormente, as épocas das coletas foram determinadas em razão da existência de brotações em tamanho e quantidade necessárias para a confecção de estacas. As avaliações realizadas constituíram-se do registro da quantidade de estacas/cepa/coleta, assim como da quantificação da sobrevivência das cepas.

\subsection{Preparo das estacas para enraizamento}

A partir das brotações das cepas, as estacas apicais foram preparadas com comprimento em torno de $15 \mathrm{~cm}$ de tamanho e as intermediárias com $12 \mathrm{~cm}$, mantendo-se dois pares de folhas reduzidas à metade de seu tamanho original. Para manter as condições de vigor e turgescência do material vegetativo, imediatamente após a coleta, as estacas foram acondicionadas em caixas de isopor com água, efetuando irrigação por meio de pulverizador manual, em intervalos de tempo inferiores a 10 minutos até a etapa de estaqueamento. O período compreendido entre a coleta das estacas, seu preparo e posterior estaqueamento foi sempre inferior a 15 minutos.

Para o enraizamento, foram utilizados, como recipiente, tubete de plástico rígido cônico de $12 \mathrm{~cm}$ de comprimento e $55 \mathrm{~cm}^{3}$ de capacidade e, como substrato, composto orgânico (MecPlant ${ }^{\circledR}$ ), acrescentando superfosfato simples $\left(8 \mathrm{~kg} \cdot \mathrm{m}^{-3}\right)$ e Osmocot ${ }^{\circledR} 19-6-10$, $\left(3 \mathrm{~kg} . \mathrm{m}^{-3}\right)$. As estacas foram dispostas no substrato, com atenção à centralização, retidão, profundidade $(2 \mathrm{~cm})$ e firmeza.

\subsection{Estabelecimento e condução dos experimentos}

Foram estabelecidos dois experimentos em diferentes épocas do ano, sendo o primeiro conduzido durante os meses de maio até outubro de 2010, denominado "E1" e o segundo, no mês de agosto de 2010 até janeiro de 2011, denominado "E2”. Os tratamentos foram testados com três dosagens de ácido indolbutírico (AIB): 0; 2.000 e $6.000 \mathrm{mg} \mathrm{L}^{-1}$, via líquida. O AIB foi preparado dissolvendo em hidróxido de sódio $(\mathrm{NaOH})$ 
e diluído em água destilada. A aplicação do AIB preparado foi submergindo à base da estaca, durante 10 segundos.

O processo de enraizamento das estacas foi conduzido em casa de vegetação climatizada, por um período de 120 dias, monitorando as condições do ambiente, visando obtenção da temperatura em torno de $28^{\circ} \mathrm{C}$ e umidade relativa do ar acima de $80 \%$. Quanto à luminosidade no interior da casa de vegetação, essa foi reduzida em $50 \%$ da luz natural, pelo uso de sombrite na parte superior da estrutura. O controle de fungos patogênicos e pragas foi feito por meio de métodos preventivos relacionados à limpeza da casa de vegetação e ao manejo do jardim clonal, assim como com aplicações periódicas com inseticida, alternando Evidence ${ }^{\circledR}(3 \mathrm{~g} / \mathrm{L})$ e Orthene ${ }^{\circledR}(1 \mathrm{~g} / \mathrm{L})$, a cada oito dias.

Após o período de enraizamento em casa de vegetação, as estacas foram aclimatadas por 20 dias em casa de sombra (sombrite de 50\%), seguindo posteriormente para uma área em pleno sol por mais 30 dias. Na saída da casa de vegetação (aos 120 dias), após o estaqueamento, foram realizadas as avaliações de sobrevivência, enraizamento (raiz observada na extremidade inferior do tubete) e vigor das estacas. Em casa de sombra (140 dias) e pleno sol (170 dias), foram realizadas as avaliações referentes a sobrevivência, enraizamento (raiz observada na extremidade inferior do tubete), vigor, altura total das mudas e quantificação da biomassa do sistema radicular e parte aérea. As avaliações de vigor das estacas foram feitas de acordo com a presença ou ausência de brotações e comprimento, utilizando uma escala de notas, em que: $1=$ Ruim: estacas vivas sem crescimento de brotações axilares; 2= Médio: estacas com brotações até $2 \mathrm{~cm}$; $3=$ Bom: estacas com brotações entre 2 e 4 cm e 4= Excelente: estacas com brotações superiores a $4 \mathrm{~cm}$.

Os tratamentos foram dispostos em delineamento de blocos casualizados (DBC), utilizando para o primeiro experimento (E1) quatro repetições com oito mudas por parcela e tipo de estaca (apical e intermediária); para o segundo (E2), utilizaram-se três repetições com 16 mudas por parcela e tipo de estaca (apical e intermediária).

\subsection{Velocidade de enraizamento das estacas}

As avaliações de velocidade de enraizamento das estacas foram feitas a cada 20 dias a partir do $30^{\circ}$ dia do estaqueamento até o $90^{\circ}$ dia; durante este período, em casa de vegetação. Conforme metodologia definida por Melo (2009), foram quantificadas, nas datas de avaliação, a porcentagem de estacas com calo e enraizadas. Consideraram-se estacas enraizadas aquelas que apresentaram raízes maiores ou iguais a $0,5 \mathrm{~cm}$ de comprimento.

Para avaliar velocidade de enraizamento foram estabelecidos mais dois experimentos, de forma pararela aos experimentos do processo de enraizamento, um sem aplicação do ácido indolbutírico (AIB) e outro com uso de $6.000 \mathrm{mg} \mathrm{L}^{-1}$ de AIB, utilizando em ambos os experimentos dois tipos de estacas (apical e intermediária). Os experimentos foram conduzidos, utilizando um delineamento de blocos ao acaso, constituído por três repetições, compostas por 40 indivíduos por parcela e tipo de estaca (apicais e intermediárias). Para cada data de avaliação, foram utilizadas 10 mudas por parcela e por tipo de estaca. Os dados obtidos referentes à porcentagem de estacas com calos foram utilizados para o ajuste da melhor função que representasse a distribuição dos dados. Já os da porcentagem de estacas enraizadas foram usados para o ajuste da função logística $Y=\alpha\left(1+\beta e^{-\gamma \mathrm{T}}\right)^{-1}$, em que $Y$ = porcentagem de enraizamento e $\mathrm{T}=$ número de dias após o estaqueamento. Conforme a metodologia descrita por Ferreira et al. (2004) e de posse da equação matemática obtida com dados de porcentual de enraizamento para cada tipo de estaca, utilizando o programa CurveExpert 1.4, foi determinado o potencial máximo de enraizamento.

\section{RESULTADOS}

\subsection{Produção e sobrevivência das cepas}

Obtiveram-se $100 \%$ de sobrevivência das cepas, desde o transplante aos canteiros até o final dos experimentos (fevereiro 2010 até janeiro 2011), evidenciando a sustentabilidade do sistema de jardim clonal, além da eficiência dos tratos culturais aplicados. O número médio de estacas/cepa/coleta aumentou gradativamente, tendo na primeira coleta média de 2,1 estacas/cepa, 3.2 na segunda, 4.8 na terceira e 5 na quarta, com uma produção de 20, 25, 36 e 38 estacas $/ \mathrm{m}^{2}$, respectivamente.

\subsection{Sobrevivência, vigor e enraizamento das estacas em casa de vegetação}

No primeiro experimento (E1), foram obtidos $100 \%$ de sobrevivência das estacas (apical e intermediária) 
em todos os tratamentos, nas avaliações na saída da casa de vegetação, indicando que as condições ambientais foram favoráveis, aliado ao alto grau de juvenilidade dos propágulos vegetativos. No caso do experimento dois (E2), as porcentagens de sobrevivência variaram entre $87 \%$ e $98 \%$, nos diferentes tratamentos e tipos de estacas (apical e intermediária); possivelmente, essa menor sobrevivência, deve-se ao fato de uma maior temperatura relacionada com a época do ano em que o experimento foi conduzido, provocando desidratação e posterior morte de algumas das estacas (Figura 1A).
Quanto ao enraizamento (raiz observada na extremidade inferior do tubete) das estacas, os valores dos dois experimentos mostraram tendência semelhante entre os tratamentos e tipos de estacas, exceto nas intermediárias do experimento E1, em que o enraizamento teve decréscimo (32\%) com a aplicação de $6.000 \mathrm{mg} \mathrm{L}^{-1}$ de AIB (Figura 1B). De modo geral, a tendência nos dois experimentos mostrou maiores porcentagens de enraizamento nas estacas sem aplicação de AIB, seguidas pelas que se aplicaram $6.000 \mathrm{mg} \mathrm{L}^{-1}$ de AIB; no caso das estacas onde se utilizaram
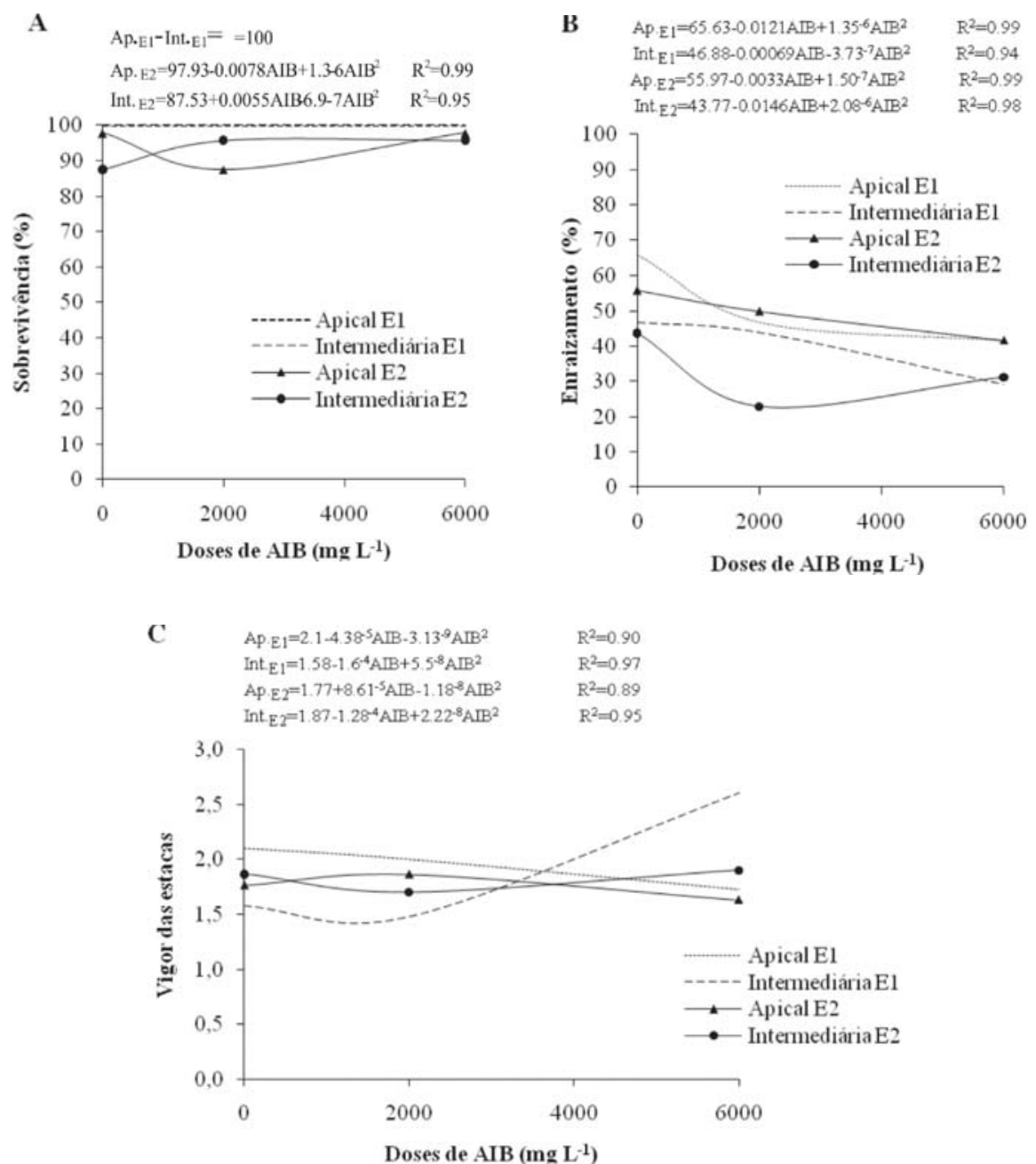

Figura 1 - Sobrevivência (A), enraizamento (B) e vigor (C) das estacas de jequitibá-rosa, em função da aplicação de ácido indolbutírico (AIB), tipo de estaca (apical e intermediária) e época de ano (E1, E2), em casa de vegetação, aos 120 dias após o estaqueamento.

Figure 1 - Survival (A), rooting (B) and vigor (C) of jequitibá-rosa cuttings, due to the application of indol-butyric acid (IBA) and type of cutting (apical stem and intermediate stem) and the period of the year $(E 1, E 2)$ in greenhouse, at120 days after establishment. 
$2.000 \mathrm{mg} \mathrm{L}^{-1}$, como tratamento, os valores de enraizamento apresentaram decréscimo em relação aos outros dois tratamentos, exceto nas estacas intermediárias do experimento E1, em que se evidenciou pequeno aumento na porcentagem de enraizamento.

Os resultados de vigor das estacas, na saída de casa vegetação, mostraram valores semelhantes entre os tipos de estacas, com tendência geral de redução desse vigor com as dosagens de AIB, exceto para as estacas intermediárias do experimento E1, que evidenciaram maior vigor (Figura 1C).

\subsection{Sobrevivência, vigor, enraizamento e altura das mudas em casa de sombra}

As estacas do experimento E1 apresentaram 100\% de sobrevivência aos 140 dias, em casa de sombra, enquanto no experimento E2, os resultados mostraram valores inferiores. (Figura 2A).

A $\begin{array}{ll}\text { Ap. - Int. } \mathrm{E}_{1}=100-4.79^{-4} \mathrm{AIB}+5.21^{-8} \mathrm{AIB}^{2} & \mathrm{R}^{2}=0.86 \\ \text { Ap. } \mathrm{E}_{2}=81-0.0099 \mathrm{AIB}+1,89-6 \mathrm{AIB}^{2} & \mathrm{R}^{2}=0.98 \\ \text { Int } \mathrm{E}_{2}=83.37+0.0008 \mathrm{AIB}+1.01^{-7} \mathrm{AIB}^{2} & \mathrm{R}^{2}=0.90\end{array}$

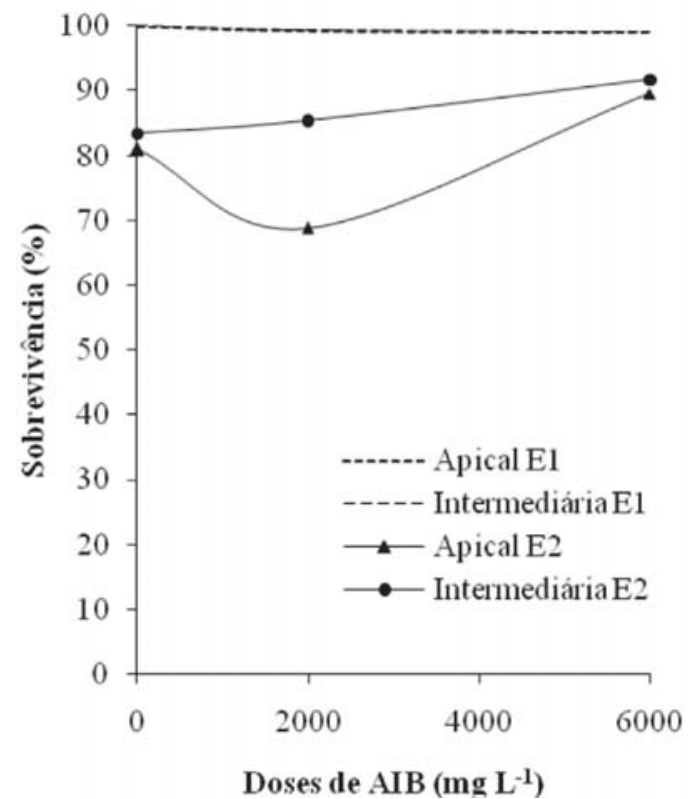

Quanto ao enraizamento (raiz observada na extremidade inferior do tubete), de modo geral, a tendência foi aumentar as porcentagens entre os diferentes tratamentos e tipos de estacas nos dois experimentos. Os resultados mostraram superioridade nos níveis de enraizamento do experimento E1, em relação aos do experimento E2 (Figura 2B).

No experimento E1, os valores de vigor das estacas (apicais e intermediárias) foram maiores em relação ao experimento E2, onde as apicais mostraram maior vigor com relação às intermediárias. Em geral, o vigor das estacas foi considerado como médio 2, exceto para as estacas intermediárias no experimento E1, do tratamento com $6.000 \mathrm{mg} \mathrm{L}^{-1}$ de AIB, que apresentaram um valor de 3, considerado como "bom” (Figura 2C). Com relação à altura, as estacas apicais apresentaram maiores valores médios em comparação às intermediárias, independentemente do tratamento e dos experimentos,

B
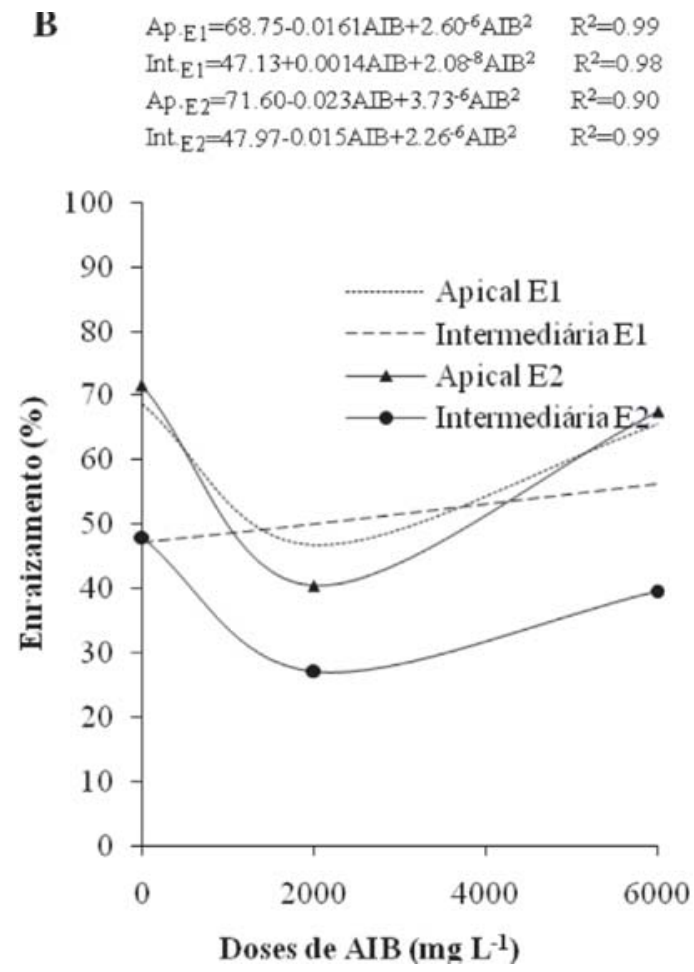

Figura 2 - Sobrevivência (A), enraizamento (B), vigor (C) e altura (D) das mudas de jequitibá-rosa, em função da aplicação de ácido indolbutírico (AIB), tipo de estaca (apical e intermediária) e época de ano (E1, E2), em casa de sombra, aos 140 dias após o estaqueamento.

Figure 2 - Survival (A), rooting (B), vigor (C) and height (D) of jequitibá-rosaplants, due to the application of indolbutyric acid (IBA) and type of cutting (apical stem, intermediate stem)and the period of the year (E1, E2) in shade house, at140 days after establishment.

Revista Árvore, Viçosa-MG, v.37, n.5, p.955-967, 2013 
mostrando maior altura no experimento E2. Quanto às estacas intermediárias, os maiores valores, em altura, para os dois experimentos não apresentaram uma tendência que permita deduzir que algum dos tratamentos influenciou significativamente a altura das mudas (Figura 2D).

\subsection{Sobrevivência, vigor, enraizamento e altura das mudas em pleno sol}

Os resultados, a pleno sol, aos 170 dias após o estaqueamento, mostraram tendência semelhante aos obtidos nas avaliações na saída da casa de sombra. Em geral, notou-se diminuição na sobrevivência nos dois tipos de estacas e nas duas épocas avaliadas, exceto para as estacas sem AIB do experimento E1, que apresentaram 100\% de sobrevivência; entretanto, nesse experimento a sobrevivência, em geral, foi superior aos $94 \%$.

No caso do experimento E2, os valores variaram entre os tratamentos e tipos de estacas, com máximo de $83,3 \%$, para as estacas apicais, e de $89,6 \%$, para as intermediárias, nos tratamentos sem AIB e $6.000 \mathrm{mg} \mathrm{L}^{-1}$, respectivamente, e mínimo de $65,8 \%$, no tratamento com $2.000 \mathrm{mg} \mathrm{L}^{-1}$, nas estacas apicais (Figura 3A).

Observa-se, no experimento E1, para as três avaliações, que as estacas apicais e intermediárias, sem AIB, mantiveram 100\% de sobrevivência até os 170 dias, após o estaqueamento, sendo as estacas com dosagem de 2.000 e $6.000 \mathrm{mg} \mathrm{L}^{-1}$ de AIB as que mostraram menor sobrevivência em pleno sol. Houve aumento no enraizamento (raiz observada na extremidade inferior do tubete), independentemente do tipo de tratamento e da época de avaliação (E1, E2), no entanto, as maiores porcentagens ocorreram nas estacas dos tratamentos sem AIB e com $6.000 \mathrm{mg} \mathrm{L}^{-1}$ (Figura 3B).

Quanto ao vigor, as estacas dos experimentos E1 e E2; sem AIB e com $6.000 \mathrm{mg} \mathrm{L}^{-1}$ apresentaram vigor médio; entretanto, as estacas com o tratamento de $2.000 \mathrm{mg} \mathrm{L}^{-1}$ de AIB, no experimento $\mathrm{E} 2$, mostraram vigor próximo a médio, com valores entre 1,5 e 2 (Figura 3C). No caso da altura, os resultados mostraram nos dois experimentos valores superiores das estacas apicais em relação às intermediárias, sendo as estacas com o tratamento de $6.000 \mathrm{mg} \mathrm{L}^{-1}$ de AIB as que apresentaram maiores valores em altura, comportamento semelhante aos resultados em casa de sombra (Figura 3D).

Quanto ao efeito da aplicação do regulador de crescimento AIB, na produção de biomassa da parte aérea e radicular, os resultados variaram entre as duas épocas de avaliação, sem mostrar tendência entre os tratamentos aplicados. Para os dois experimentos, as estacas apicais mostraram maiores valores de biomassa da parte aérea e radicular, em relação às intermediárias, indicando maior desenvolvimento e vigor vegetativo, possivelmente produto de um maior grau de juvenilidade (Figuras 4A e B), sendo superiores aqueles valores do experimento E1.

\subsection{Velocidade de enraizamento das estacas}

As porcentagens de calo nas estacas apicais e intermediárias, com $6.000 \mathrm{mg} \mathrm{L}^{-1}$ de AIB e para as sem AIB foram ajustadas aos modelos que melhor representaram sua distribuição. Os resultados indicam maior presença de calo nas estacas intermediárias em relação às apicais, durante o período de avaliação. Aos 30 dias após o estaqueamento, as intermediárias apresentaram 95\% e $100 \%$ de calo com e sem AIB, respectivamente. No caso das estacas apicais, a porcentagem de calo, no mesmo tempo, foi de $37 \%$ e $52 \%$ para as estacas com e sem aplicação de AIB, respectivamente (Figuras 5A e B).

Para os dois tipos de estacas, a porcentagem de calos apresenta comportamento descendente no tempo, com e sem AIB, justificado pelo fato de que a porcentagem de enraizamento aumenta, diminuindo a quantidade de estacas com presença de calo (Figuras 5A e B).

Com relação ao enraizamento até aos 50 dias após o estaqueamento, as estacas apicais enraizaram-se mais rápido, atingindo $50 \%$ de enraizamento para as estacas com aplicação de AIB (6.000 $\mathrm{mg} \mathrm{L}^{-1}$ ) e 40\% para as estacas sem aplicação de AIB (Figuras 5C e D). A partir dos 50 dias, o enraizamento entre os tipos de estaca com aplicação de AIB é muito semelhante, momento em que as estacas intermediárias mostraram acréscimo nas porcentagens de enraizamento, apresentando $82 \%$, aos 90 dias, em contraste com as apicais, que apresentaram 56\%. As estacas sem AIB apresentaram comportamento diferente entre os tipos de estacas, com relação aos resultados do experimento com regulador de crescimento, onde mostrou-se superioridade das estacas apicais em relação às intermediárias, atingindo um ponto máximo, de acordo com a estimação do modelo de regressão aos 75 dias, com 76,8\% de enraizamento. Já aos 90 dias após o estaqueamento, as intermediárias apresentaram acréscimo, mostrando maior porcentagem de enraizamento que as apicais.

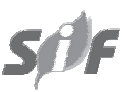

Revista Árvore, Viçosa-MG, v.37, n.5, p.955-967, 2013 
A
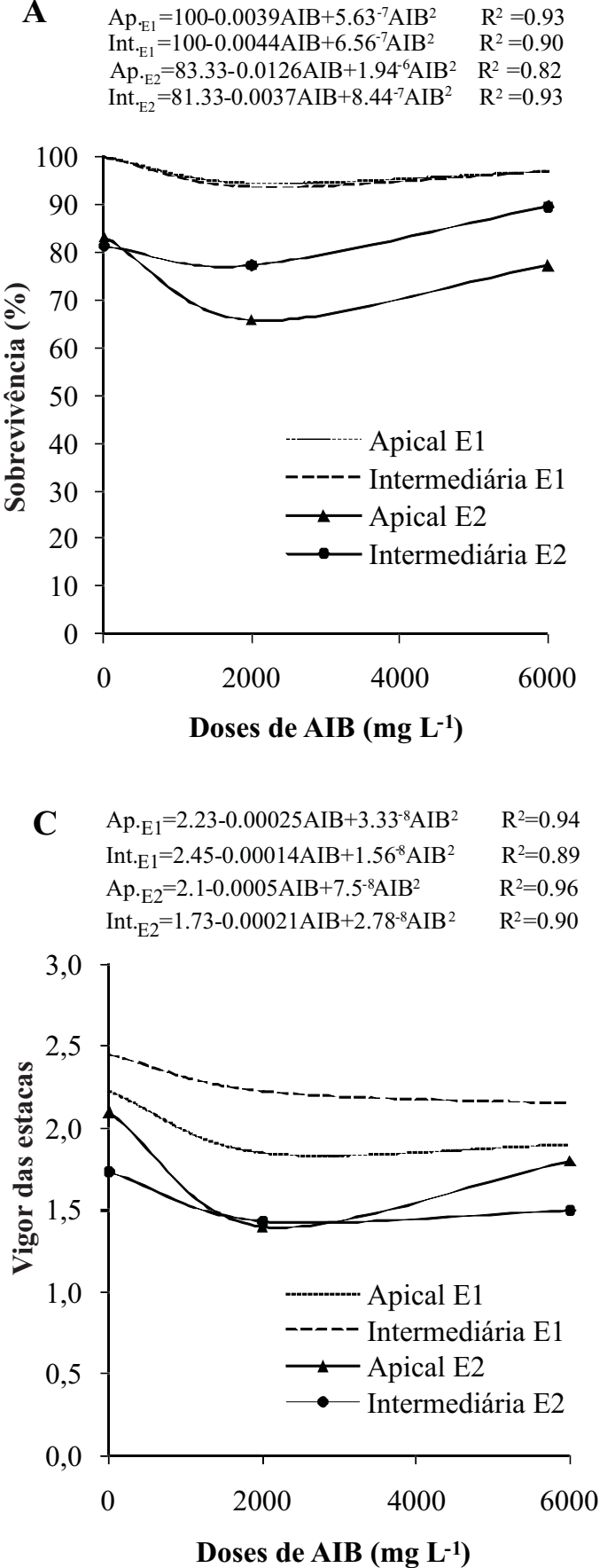
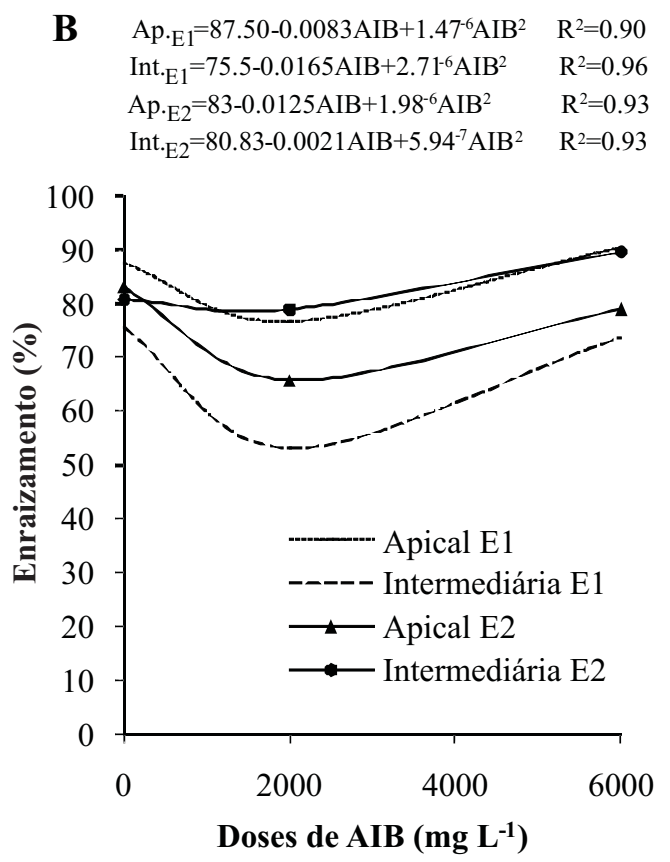

D

Ap.E1 $=11.08-0.00019 \mathrm{AIB}+5.73^{-8} \mathrm{AIB}^{2} \quad \mathrm{R}^{2}=0.95$ Int $\mathrm{El}_{1}=9.78-0.0011 \mathrm{AIB}+2.11^{-7} \mathrm{AIB}^{2} \quad \mathrm{R}^{2}=0.90$ Ap. $\mathrm{E}_{2}=12.87+0.0008 \mathrm{AIB}-1.35^{-7} \mathrm{AIB}^{2} \quad \mathrm{R}^{2}=0.97$ Int. ${ }_{2}=10.60-0.0009 \mathrm{AIB}+1.26^{-7} \mathrm{AIB}^{2} \quad \mathrm{R}^{2}=0.97$

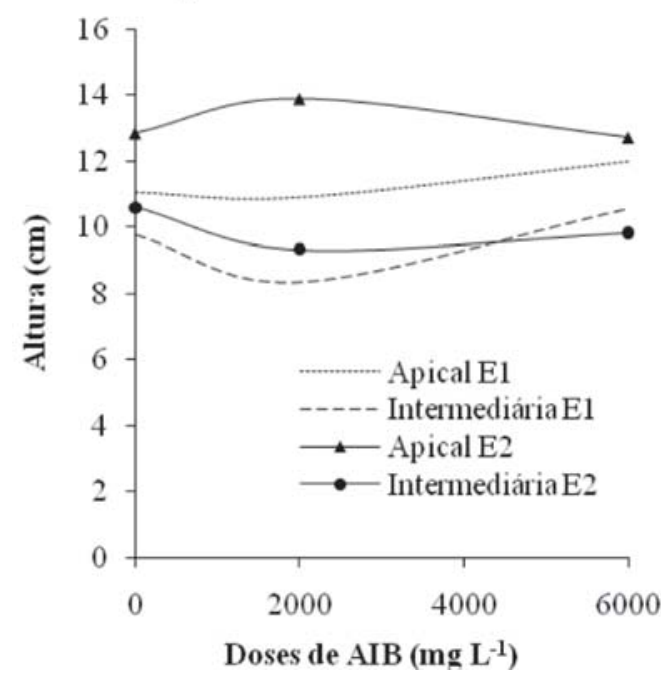

Figura 3 - Sobrevivência (A), enraizamento (B), vigor (C) e altura (D) das mudas de jequitibá-rosa, em função da aplicação de ácido indolbutírico (AIB), tipo de estaca (apical e intermediária) e época do ano (E1, E2), em pleno sol, aos 170 dias após o estaqueamento.

Figure 3 - Survival (A), rooting (B), vigor (C) and height (D) of jequitibá-rosaplants, due to the application of indolbutyric acid (IBA), type of cutting (apical stem, intermediate stem)and the period of the year (E1, E2) atfull sun, at 170 days after establishment.

Revista Árvore, Viçosa-MG, v.37, n.5, p.955-967, 2013 
A

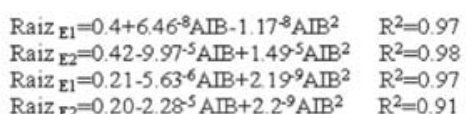

Raiz $\mathrm{E}_{\mathbf{2}}=0.20-2.28^{-5} \mathrm{AIB}+2.2^{-9} \mathrm{AIB}^{2} \quad \mathrm{R}^{2}=0.91$

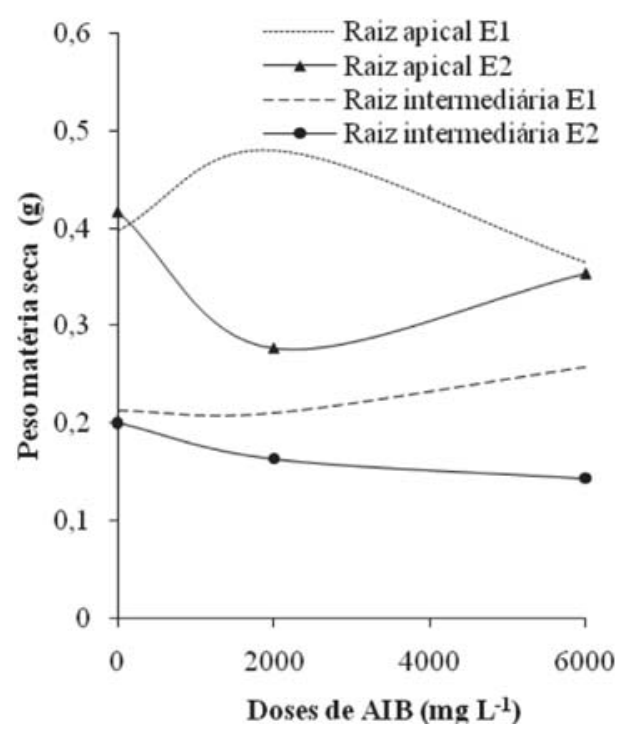

B

Folha $a_{11}=0.81+2 \cdot 19^{-5} \mathrm{AIB}-4 \cdot 69^{-9} \mathrm{AIB}^{2} \quad \mathrm{R}^{2}=0.89$ Folha $\mathrm{E}_{2}=0.79-0.00011 \mathrm{AIB}+2.43^{-8} \mathrm{AIB}^{2} \quad \mathrm{R}^{2}=0.99$ Folha ${ }_{\mathrm{E} 1}=0.63-3.88^{-5} \mathrm{AIB}+9.38^{-9} \mathrm{AIB}^{2} \quad \mathrm{R}^{2}=0.97$ Folha ${ }_{E_{2}}=0.75-0.00012 \mathrm{AIB}+1.38^{-8} \mathrm{AIB}^{2} \quad \mathrm{R}^{2}=0.99$

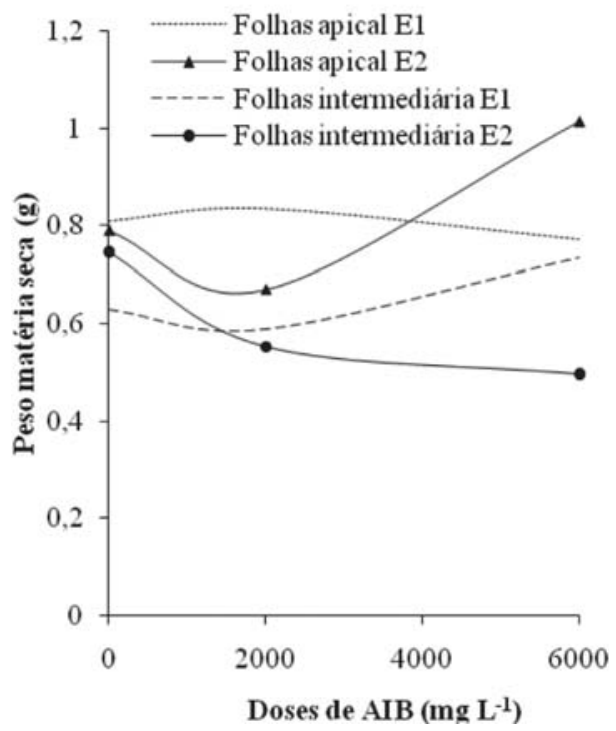

Figura 4 - Peso de massa seca do sistema radicular (A) e parte aérea (B) das mudas de jequitibá-rosa, em função da aplicação de ácido indolbutírico (AIB), tipo de estaca (apical e intermediária) e época do ano (E1, E2), aos 170 dias após o estaqueamento.

Figure 4 -Dry matter weight of the rooting system (A) and aerial part (B) of jequitibá-rosaplants, due to the application of indo-butyric acid (IBA), type of cutting (apical stem and intermediate stem) and period of the year (E1, E2) at170 days after establishment.

\section{DISCUSSÃO}

\subsection{Produção e sobrevivência das cepas}

O aumento gradativo da produção de estacas/cepa/ coleta pode ser explicado pelo fato de que, após a primeira coleta, com a quebra da dominância, houve estímulo à brotação das cepas, e as variações das condições climáticas (temperatura, precipitação e insolação), em razão das mudanças das estações do ano. Porém, outro aspecto a considerar é o tempo que transcorreu entre uma coleta e outra, fator que também pode influenciar na produção de estacas. Esses resultados indicam o potencial do jequitibá-rosa, quanto à regeneração vegetativa das cepas, em função das sucessivas coletas das estacas, permitindo a adoção da estaquia como alternativa potencial na propagação dessa espécie. Além disso, a técnica adotada permite um planejamento mais adequado, visando atender à determinada demanda, nas diferentes épocas do ano, estruturas e condições ambientais variadas (XAVIER et al., 2003).

\subsection{Casa de vegetação}

Houve tendência predominante na sobrevivência entre os dois tipos de estacas utilizados nos experimentos, mostrando porcentagens relativamente altas nos dois casos. Esses resultados concordam com os obtidos por Santos (2002) e Gatti (2002), os quais, trabalhando com a espécie Cariniana estrellensis, utilizando a técnica de miniestaquia, obtiveram porcentagens de sobrevivência superiores a 90\%, mostrando o potencial da propagação vegetativa de jequitibá-rosa, em virtude da alta sobrevivência em casa de vegetação, em condições de umidade e temperatura relativamente controladas, além das características do substrato utilizado para o enraizamento.

\subsection{Casa de sombra}

Os resultados dos dois experimentos, na saída de casa de sombra, não mostraram grandes diferenças; porém, houve diminuição dos valores médios das 
características avaliadas no segundo experimento, que pode ser atribuída, em parte, às mudanças das condições ambientais, início de verão, quando as condições de temperatura e luminosidade variam significativamente, sendo diferente da época em que se avaliou o experimento
E1 (ao final de inverno), o que pode ter influenciado na sobrevivência das estacas. As estacas apicais, independentemente do tratamento e dos experimentos (época de ano), mostraram maior enraizamento em relação às intermediárias, indicando a importância desse tipo

$\begin{array}{ll}\text { A Ap }=-0.60+3.42^{*} \mathrm{~T}+-0.09^{*} \mathrm{~T} *+0.0006^{*} \mathrm{~T} & \mathrm{R}^{2}=0.95 \\ \text { Int }=25.53\left(1-4.43 \exp ^{\left(-0.599^{*}+\mathrm{T}\right)}\right. & \mathrm{R}^{2}=0.96\end{array}$

B Ap $=0.11+4^{*} \mathrm{~T}-0.093^{*} \mathrm{~T}^{2}+0.0006^{*} \mathrm{~T}^{3} \quad \mathrm{R}^{2}=0.99$

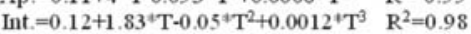
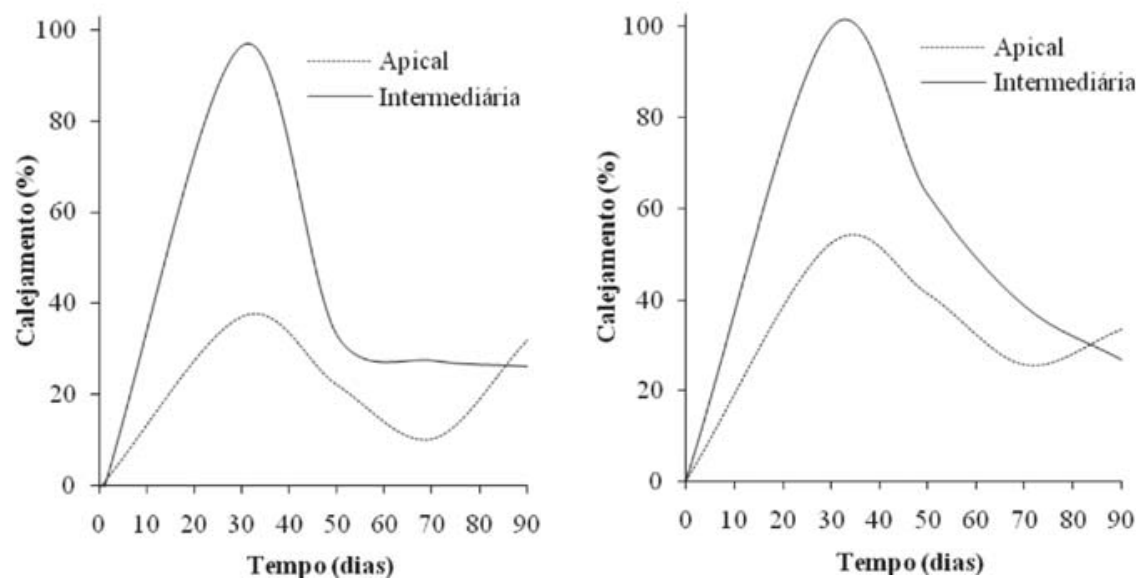

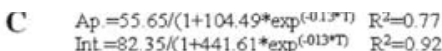

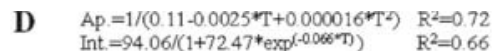
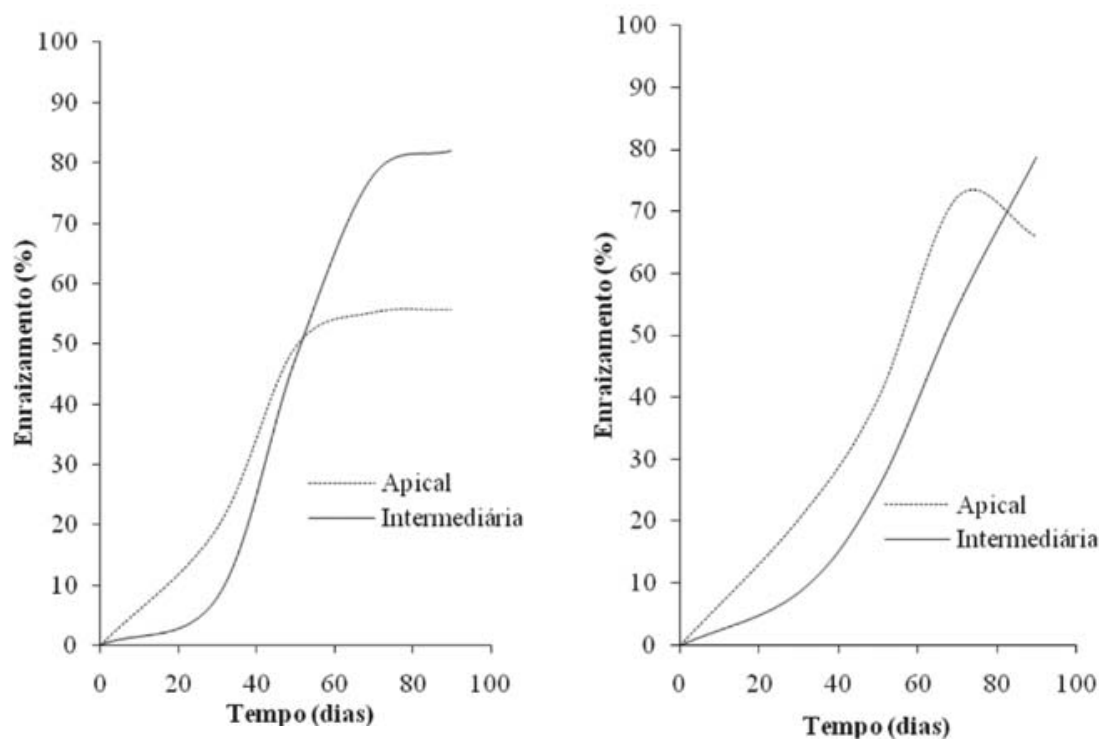

Figura 5 - Porcentagem de calejamento (A e B) e de enraizamento (C e D) das estacas de jequitibá-rosa, com aplicação de $6.000 \mathrm{mg} \mathrm{L}^{-1}$ de AIB (A e C) e sem AIB (B e D), em função do tipo de estaca (apical e intermediária) e tempo após o estaqueamento.

Figure 5 - Percentage of callus (A and B) and of rooting ( $C$ and D) of jequitibá-rosacuttings, with application of $6.000 \mathrm{mg} \mathrm{L}^{-1}$ of IBA (A and C) and without (B and D)due to the type of cutting (apical stem and intermediate stem) and time after establishment.

Revista Árvore, Viçosa-MG, v.37, n.5, p.955-967, 2013 
de estacas para a propagação vegetativa de jequitibárosa, em virtude da alta sobrevivência e do maior enraizamento em casa de vegetação e sombra.

\subsection{Pleno sol}

A diferença na sobrevivência entre os experimentos, ainda que mínima, pode estar relacionada com a época de ano em que foram avaliados, principalmente no experimento E2, onde o aumento da temperatura, poderia gerar perda excessiva de água, em razão do comprometimento na manutenção das folhas, das gemas e dos ramos (XAVIER et al., 2009). As diferenças, em relação aos efeitos das dosagens de AIB podem ser explicadas pelo fato de tratar-se de material juvenil, oriundo de plantas produzidas por sementes, onde o balanço hormonal interno mostra-se favorável para o enraizamento, ocasionando resposta pouco expressiva às aplicações de regulador de crescimento (SOUZA JUNIOR et al., 2008). Segundo Xavier et al. (2009), os ganhos advindos da aplicação dos reguladores de crescimento têm sido mais frequentes em materiais com maior dificuldade de enraizamento, seja por questões genéticas ou em razão do estágio de maturação dos propágulos. De acordo com Hartmann et al. (2002), quando a auxina é aplicada em estacas, ocorre aumento da sua concentração, produzindo efeito estimulador de raízes até o ponto máximo, a partir do qual qualquer acréscimo de seu nível se torna inibitório, requerendo mais estudos com outras concentrações de AIB, nas diferentes épocas do ano.

A concentração ótima do regulador de crescimento é variável, de acordo com a espécie e o tipo de estaca utilizado. Estudos com espécies florestais nativas, utilizando a técnica de estaquia, têm mostrado grandes variações na capacidade de enraizamento. Estacas de corticeira-do-banhado (Erythrina crista-galli) apresentaram variações de enraizamento de 0 a $100 \%$, aos 60 dias, em função do tipo de estaca utilizado (CHAVES et al., 2003). Em estacas de pau-brasil (Caesalpinia echinata Lam.), os valores médios de enraizamento foram de $15 \%$, com uso de AIB, e 16\%, usando ácido naftalenoacético (ANA), aos 120 dias (MARROQUIM et al., 2005). De acordo com Oliveira et al. (2003), para o enraizamento de estacas de pessegueiros, são necessários $2.000 \mathrm{mgL}^{-1}$ de AIB, enquanto, para estacas de acácia (Acacia mearnsii De Wild), concentrações inferiores a $1.000 \mathrm{mgL}^{-1} \mathrm{de}$ AIB apresentaram melhores resultados no enraizamento (BORGES; MARTINSCORDER, 2000).
Em estudos com candeia, Eremanthus erythropappus, Goulart (2003) observou a inviabilidade de propagação vegetativa, por causa do baixo enraizamento, independentemente da utilização de reguladores de crescimento. Wendling e Souza Junior (2003) observaram que para miniestacas de erva-mate (Ilex paraguariensis St.Hil.), a partir de material de origem seminal, é tecnicamente viável, atingindo-se valores médios de $75 \%$ de sobrevivência aos 120 dias de idade das mudas, sem a necessidade de aplicação de reguladores de crescimento para o enraizamento. Analisando os dois experimentos, os resultados não mostraram tendência definida com respeito aos efeitos do AIB na produção de biomassa; no entanto, de forma geral, segundo a época do ano, verificam-se efeitos superiores nas estacas com AIB. Segundo Cleland (1995), esse fato pode ser explicado em razão da auxina facilitar o movimento de solutos para zonas de crescimento. Também Araújo et al. (2005) observaram efeito quadrático do AIB em estacas de figueira (Ficus carica $L$.), refletido pelo número de folhas produzidas e pela produção de raízes.

\subsection{Velocidade de enraizamento das estacas}

A aplicação de AIB favoreceu o enraizamento das estacas intermediárias e inibiu nas apicais, mostrando maiores porcentagens de enraizamento nas estacas sem aplicação de AIB, antes dos 70 dias, após o estaqueamento. O conhecimento sobre a velocidade de enraizamento das estacas determina sua permanência em casa de vegetação, o que pode influenciar sobre outros aspectos advindos à propagação vegetativa, no caso do jequitibá-rosa.

Segundo Ferreira et al. (2004), o ajuste de modelos que expressam o enraizamento de diferentes propágulos pode minimizar os custos, em virtude da otimização da utilização das instalações e da redução das perdas por doenças, uma vez que não será preciso a permanência dos propágulos, sob condições favoráveis à incidência de doenças por tempo, além daquele requerido para iniciar o processo rizogênico.

Os resultados obtidos podem variar por causa das condições ambientais, como época do ano, temperatura, umidade, assim como o tipo de propágulo utilizado e o estado morfofisiológico. Segundo Pio et al. (2003), vários fatores podem influenciar o enraizamento das estacas, tanto intrínsecos, relacionados à própria planta, quanto extrínsecos, ligados às condições ambientais; mesmo assim, a dificuldade no enraizamento

Revista Árvore, Viçosa-MG, v.37, n.5, p.955-967, 2013 
de estacas de algumas espécies pode ser superada se fornecidas as condições ótimas para o enraizamento.

\section{CONCLUSÕES}

È tecnicamente viável a propagação vegetativa do jequitibá-rosa, por enraizamento, de estacas provenientes de cepas de material de origem seminal. O ácido indolbutírico (AIB) teve pouca influência na propagação do jequitibá-rosa por estaquia. A concentração de $6.000 \mathrm{mg} \mathrm{L}^{-1}$ mostrou maior velocidade e porcentagem de enraizamento nas estacas intermediárias; entretanto, para as apicais, a aplicação de AIB não é necessária.

As estacas apicais apresentaram maior potencial de enraizamento, em relação às intermediárias. A época do ano influenciou na propagação vegetativa do jequitibárosa, mostrando, de forma geral, valores médios superiores nas características avaliadas aos obtidos no período de maio a outubro. As cepas apresentaram 100\% de sobrevivência, com tolerância a sucessivas coletas de estacas e com produção crescente de brotações no tempo, mostrando a capacidade regenerativa da espécie.

\section{REFERÊNCIAS}

AlfEnAS, A. C. et al. Clonagem e doenças do eucalipto. Viçosa, MG: Universidade Federal de Viçosa, 2004. 442p.

ARAÚJO, J. P. C. et al. Propagação da figueira por estaquia tratadas com AIB. Bioscience Journal, v.21, n.2, p.59-63, 2005.

ASSIS, T. F. Propagação vegetativa de Eucalyptus por microestaquia. In: IUFRO CONFERENCE ON SILVICULTURE AND IMPROVEMENT OS EUCALYPTUS, 1997, Salvador. Proceedings... Colombo: Embrapa, 1997.v. 1. p.300-304.

BORGES, N. J.; MARTINS-CORDER, M. P. Efeito do ácido indolburítico no enraizamento de estacas de Acácia Negra (Acacia mearnsii De Wild) In: CONGRESSO E EXPOSIÇÃO INTERNACIONAL SOBRE FLORESTAS, 6., 2000, Porto Seguro. Anais... Porto Seguro: 2000. p.109.

CARVALHO, P. E. R. Espécies florestais brasileiras: recomendações silviculturais, potencialidades e uso da madeira. Colombo: Embrapa - CNPF, Brasília: Embrapa - SPI, 1994. p.407-409.
CHAVES, C. R. M. et al. Enraizamento de 5 tipos de estacas caulinares de corticeira-do-banhado. In: CONGRESSO BRASILEIRO DE FISIOLOGIA VEGETAL, 9., 2003, Campinas. Anais... Campinas: 2003. v.15. p.135.

CLELAND, R. E. Auxin and cell elongation. In: DAVIES, P. J. (Ed.). Plant hormones: physiology, biochemistry and molecular biology. 2.ed. New York: 1995. p.214-227.

FERREIRA, E. M. et al. Determinação do tempo ótimo do enraizamento de miniestacas de clones de Eucalyptus spp. Revista Árvore, v.28, n.2, p.183-187, 2004.

GATTI, K. C. Propagação vegetativa de pau mulato (Calycophyllum spruceanum (Benth) K. Schum.) jequitibá (Cariniana estrellensis (Raddi) Kuntze) e teca (Tectona grandis Linn. F.) por miniestaquia. 2002. 72f. Dissertação (Mestrado em Ciência Florestal) - Universidade Federal de Viçosa, Viçosa, MG, 2002.

GOULART, P. B. Desenvolvimento de metodologia para enraizamento de estacas de candeia (Eremanthus erythropappus (DC) MacLeish). Lavras: Universidade Federal de Lavras, 2003. 32p.

HARTMANN, H. T. et al. Plant propagation: principles and practices. 7.ed. New Jersey: Prentice-Hall, 2002. 890p.

MARROQUIM, P. M. G. et al. Propagação vegetativa de pau-brasil (Caesalpinia echinata Lam.) com o uso de auxinas. In: CONGRESSO BRASILEIRO DE FISIOLOGIA VEGETAL 10.; CONGRESSO LATINO AMERICANO DE FISIOLOGIA VEGETAL, 12., 2005, Recife. Anais... Campinas: Sociedade Brasileira de Fisiologia Vegetal, 2005. CD ROM.

MELO, L. A. Armazenamento, aplicação de antioxidantes e otimização do tempo em casa de vegetação no enraizamento de miniestacas de híbridos de Eucalyptus grandis 2009. 58f. Dissertação (Mestrado em Ciência Florestal) Universidade Federal de Viçosa, Viçosa, MG, 2009.

LORENZI, H. Árvores brasileiras: manual de identificação e cultivo de plantas arbóreas do Brasil. 4.ed. Nova Odessa: Plantarum, 2002. v.1. 368p. 
OLIVEIRA, A. P.; NIENOW, A. A.; CALVETE, E. O. Capacidade de enraizamento de estacas semilenhosas e de cultivares de pessegueiro tratadas com AIB. Revista Brasileira de Fruticultura, v.25, n.2, p.282-285, 2003.

PAIVA, N. H.; GOMES, J. M. Propagação vegetativa de espécies florestais. Viçosa, MG: Universidade Federal de Viçosa, 2005. 46p. (Cadernos Didáticos, 83).

PIO, R. et al. Enraizamento de estacas apicais de figueira tratadas com sacarose e ácido indolbutírico por imersão rápida. Revista

Brasileira Agrociência, v.9, n.1, p.35-38, 2003.

ROCHA, M. G. B. Melhoramento de espécies arbóreas nativas. Belo Horizonte: Instituto Estadual Florestal Sustentável - IEF/MG, 2002.173p.

ROCHA, V. M.; FIALHO, E. S. Uso da terra e suas implicações na variação termo-higrométrica ao longo de um transeto campo-cidade no município de Viçosa-MG. Revista de Ciencias

Humanas, v.10, n.1, p.64-77, 2010.
SANTOS, G. Miniestaquia na clonagem de jequitibá, mogno, cedro e canjerana. 2002. 70f. Monografia (Graduação) Universidade Federal de Viçosa, Viçosa, MG, 2002.

SOUZA JUNIOR, L.; QUOIRIN, M.; WENDLING, I. Miniestaquia de Grevillea robusta A. Cunn. a partir de propágulos juvenis. Ciência Florestal, v.18, n.4, p.455-460, 2008.

WENDLING, I.; SOUZA JUNIOR, L. Propagação vegetativa de erva-mate (Ilex paraguariensis Saint Hilaire) por miniestaquia de material juvenil. In: CONGRESSO SUL-AMERICANO DA ERVAMATE, 3., 2003, Chapecó; FEIRA DO AGRONEGÓCIO DA ERVA-MATE, 2003, Chapecó. Anais... Chapecó: EPAGRI, 2003.

XAVIER, A.; SANTOS, G. A.; OLIVEIRA, M. L. Enraizamento de miniestaca caulinar e foliar na propagação vegetativa de cedro-rosa (Cedrela fissilis Vell.). Revista Árvore, v.27, n.3, p.351-356, 2003.

XAVIER, A.; WENDLING, I.; SILVA, R. L. Silvicultura clonal: princípios e técnicas. técnicas.Viçosa, MG: Universidade Federal de Viçosa, 2009. 272p. 
